\title{
Investigation of Genetic Diversity in Afghan Bread Wheat Genotypes Using SSR and AFLP Markers
}

\author{
Mohammad Bahman Sadeqi ${ }^{1,2, a,{ }^{,},}$, Said Dadshani ${ }^{3, b}$, Mohammad Yousefi ${ }^{4, c}$, Gul Mohammad Ajir ${ }^{4, d}$ \\ ${ }^{1}$ Department of Biotechnology and Seed Production, Faculty of Agriculture, Kabul University, Afghanistan \\ ${ }^{2}$ Institute of Crop Science \& Resource Conservation (INRES)-Plant Breeding, University of Bonn, Germany \\ ${ }^{3}$ Institute of Crop Science \& Resource Conservation (INRES)-Plant Breeding, University of Bonn, Germany \\ ${ }^{4}$ Department of Biotechnology and Seed Production, Faculty of Agriculture, Kabul University, Afghanistan
}

* Corresponding author

\section{A R T I C L E IN F O}

Research Article

Received : 03/08/2018

Accepted : 20/05/2019

\section{Keywords:}

Genetic diversity

Bread wheat

Molecular markers

SSRs

AFLPs
A B S T R A C T

Genetic diversity assessment is the principle component for conservation and characterization of germplasm. Genetic diversity study of Afghan bread wheat genotypes is a first step to identify and to select high performance genotypes and distribute to wheat breeding programs. The main objective of this study is to investigate of genetic diversity in 35 Afghan bread wheat genotypes by using Simple Sequence Repeat (SSR) and Amplified Fragment Length Polymorphism (AFLP) markers. DNA extraction according to Cetyl Trimethyl Ammonium Bromide (CTAB) method was conducted and the total genomic DNA was isolated from each variety. Sixty-four SSR primer markers were used and eighteen EcoRI $+(\mathrm{N}) / \mathrm{MseI}+(\mathrm{N})$ primer combinations with their primer sequences were used for selective polymerase chain reaction (PCR) amplification. Every SSR and AFLP fragment was scored as present (1) or absent (0) within all genotypes under study. Marker/ Value ratio of pairwise genetic distance between genotypes according to the SSRs data was from 0.508 to 0.691 with an average distance of 0.599 . Relatively different grouping pattern in comparison to AFLP data observed through cluster analysis. Both types of molecular markers (AFLP and SSR) used in this research proved to be suitable for investigating genetic diversity in the genotypes of Afghan bread wheat, however, AFLP markers gave better view of genetically relationships among genotypes than the SSR markers. The grouping generated by AFLP data showed a special agreement with the origin regions of genotypes (Ariana-07 and Mazar-99 originating from the north of Afghanistan, Lalmi-03 and Kabul-02. Large number of DNA bands identified with AFLP markers might provide a better estimation of genetic similarity than those of SSR markers.

\footnotetext{
a@mbsadeqi@uni-bonn.de

$\begin{array}{ll}\text { mbsadeqi@uni-bonn.de } & \text { (iD) https://orcid.org/0000-0002-8991-812X } \\ \text { yousefymohammad@gmail.com } & \text { (iD) https://orcid.org/0000-0001-5951-256X }\end{array}$

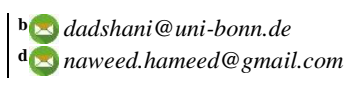

(iD) https://orcid.org/0000-0001-9194-1372

(iD) https://orcid.org/0000-0001-7565-4250
}

\section{Introduction}

Agriculture sector is the backbone of Afghanistan economy for sustainability and food security. Afghanistan produces about 2.3 million hectares wheat (Triticum aestivum $\mathrm{L}$.) as a staple cereal food and has about 40 wheat varieties in its seed chain (FAO, 2017). Collecting wheat germplasm from specific geographic region will show high genetic variation. A study of genetic diversity among adapted varieties or elite genotypes breeding materials has a significant impact on crop improvement used for germplasm management and genotype selection for different breeding purposes (Fufa et al., 2005).

Genetic diversity assessment is a principle component for conservation and characterization of germplasm (Wenguang et al., 1998). Genetic diversity is based on pedigree analysis, phenotypic data or molecular markers. In each gene pool genetic drift, selection pressure and the relatedness of ancestors without a known pedigree are important to investigation of genetic diversity based on pedigree analysis (Soleimani et al., 2002). Different morphological and physiological traits have been studied as selection items for wheat breeding programs (Casadesus et al., 2007; Naghavi et al., 2007), but these studies have some serious limitation including low heritability and polymorphism and late expression may be controlled by pleiotropic gene effects and epistasis (Van Beuningen and Busch, 1997). These limitations made these markers to be replaced by DNA based markers such as Restriction Fragment Length Polymorphisms (RFLPs), Random Amplified Polymorphic DNA (RAPD), Amplified Fragment Length Polymorphisms (AFLP), and Simple Sequence Repeats (SSRs). Using molecular markers is a complementary method to analyze genetic variation in different crop plants and wild type species because they are not influenced by pleiotropic gene effects and epistasis. In addition, in term of cost, polymorphism, reproductively and genetic distance estimation are very different, and 
breeder can choose each of them by considering advantages and disadvantages of them (Gupta et al., 1996; Prasad et al., 2000). SSR markers is frequently used in most plant genomes and can be highly informative and reproducible (Gupta et al., 1996). Although AFLP analysis is laborious and time consuming, it can detect many polymorphisms with each specific primer combination (Mardi et al., 2006).

In recent years, low yield per unit area, low quality of bread wheat, lack of research activities on wheat as a staple food and lack of certified seeds for farmers are the biggest challenges of wheat production in Afghanistan. Therefore, a study of genetic diversity of Afghan bread wheat genotypes is first step to identify and selecting high performance genotypes and to distribute to wheat breeding programs. The main objective of this study is to investigate of genetic diversity in 35 Afghan bread wheat genotypes by using SSR and AFLP markers.

\section{Material and Methods}

\section{Plant Materials}

Previously we gathered more than 250 cultivars and advanced lines (such as landraces, elite genotypes, generation of the advanced backcross populations or recombinant inbreed lines) from Afghanistan's Ministry of Agriculture, Irrigation and Livestock, ICARDA and CIMMYT region offices in the country and other international related organization. This study was conducted in agriculture research farms in Kabul University and Badam Bagh, during three wheat harvesting seasons 2014-2015, 2015-2016 and 2016-2017. The genetic materials include thirty-five different local wheat genotypes adapted and introduced by Afghanistan's Ministry of Agriculture, Irrigation and Livestock. These common genotypes had good agronomic characteristics and performed well under Kabul agro-ecological conditions in recent years. More descriptions of these genotypes is presented in Table 1 .

\section{DNA Extraction}

To obtain material for DNA extraction, according to Cetyl Trimethyl Ammonium Bromide (CTAB) method (Saghai-Maroof et al., 1984), 5 seeds of each examined genotypes were germinated and allowed to develop for 3 weeks under glasshouse conditions. Five cm leaf segments were picked up from each genotypes and used to create a pooled leaf sample. The leaf tissue was used to extract DNA. The final DNA pellet was suspended in $50 \mu \mathrm{L}$ TE buffer (10 mM TRIS-HCl, pH 8.0; 1 mM EDTA).

Table 1 The Descriptions of Afghan Common Wheat Genotypes Used in This Research (2014-2017).

\begin{tabular}{|c|c|c|c|}
\hline Genotype Name & Source & $\begin{array}{l}\text { Growth } \\
\text { Type }\end{array}$ & Pedigree \\
\hline Solh-02 & CIMMYT & Winter & OK82282//BOW//NKT/F4/ \\
\hline Gul-96 & ICARDA & Winter & ID8009994.W./VEE 2WM-OWM-OSE-1YCOYC \\
\hline Ghazna-97 & CIMMYT & Winter & AGRI/NAG \\
\hline Bakhtawar-92 & CIMMYT & Winter & JUP/BJY/URES CM7458-4Y-1M-3Y-08-OSY \\
\hline Ghori-96 & CIMMYT & Spring & PRL"S"/PEW CM59377-3AP-1AP-3AP-2AP- 1AP-OAP \\
\hline HD-2285 & CIMMYT & Spring & HD1912-1592/hd1962E4870-K65XHD2160/ HD2186 \\
\hline Inqlab-91 & Pakistan & Spring & PB19545-9A-0A-OPAK \\
\hline Balkh-66 & India & Spring & HD-2232 \\
\hline Nangarhar-64 & CIMMYT & Spring & WL-711 \\
\hline Chonte & Afghanistan & Winter & SERI.1B*2/3/KAUZ*2/BOBWHITE//KAUZ/4/PBW 343*2/KUKUNA[3692] \\
\hline PBW-154 & India & Spring & HD2177/HD2160 \\
\hline Takhar-96 & CIMMYT & Spring & VEE\#7/OPATA \\
\hline Snb-01 & CIMMYT & Spring & Snb's'/5/Maya74's'/On//II60.147/3/Bb/GII/4/Chat's' \\
\hline HUW-234 & India & Spring & HUW12/Sparrow/HUW12 \\
\hline Dayma-96 & CIMMYT & Spring & HD2206/HORK//BUC/BUL \\
\hline MH-97 & Pakistan & Spring & Attila CM8583-504-OM-OY-OSY-OAP \\
\hline Rana-96 & ICARDA & Facultative & $\begin{array}{l}\text { CA8055/6/PATOR/CAL/3/76//BB/CN015/CAL//CNOSN64/4/CNO//NAD/CH } \\
\text { 2AP-2AP-2AP-1AP-OAP }\end{array}$ \\
\hline Irena/Weaver & CIMMYT & Facultative & IRENA/Weaver/CMBW90M294.1-1M-020Y-010M-010Y-6M-015Y-0Y \\
\hline Lalmi-03 & ICARDA & Facultative & FLORKWA-3 IC84-0074-02AP-3002-1APOL-OAP \\
\hline Sheshambagh- 08 & CIMMYT & Facultative & SW89.5181/KAUZ \\
\hline Ariana- 94 & Afghanistan & Winter & $\begin{array}{l}\text { BOBWHITE/NACOZARI-76//VEERY/3/BLUEJAY/COCORAQUE- } \\
\text { 75[1922]; CHINA-13//GLENNSON-M-81[3589] }\end{array}$ \\
\hline Amu-99 & ICARDA & Facultative & Bloyka-ICW84-0008-013AP-300L-OAP \\
\hline Kabul-02 & Afghanistan & Facultative & HD-3280 \\
\hline Darulaman-07 & CIMMYT & Facultative & Weaver/4/Nac/Th.ac//3*PVN/3/mirlo/bucCID/SID:133428/104 \\
\hline Roshan-96 & ICARDA & Facultative & BLOUNDAN/3/Bb/7C*2//Y50E/KAL*3 \\
\hline Mazar-99 & ICARDA & Facultative & PASTURE CM85295-0101TOPY-2M-OYOM- 3Y-OM \\
\hline Herat-99 & ICARDA & Facultative & MYNA/VUL//PRL CM97958-OM-7Y-030M-030M-84-OM \\
\hline Croc- 01 & CIMMYT & Facultative & CROC_1/AE.SQ (205) KAUZ/3/PASTOR \\
\hline Drokhshan-08 & CIMMYT & Facultative & CNDO/R143/ENTE/MEXI_2/3/ \\
\hline Parvan-02 & CIMMYT & Facultative & CHTO/ARDEA//SRN_2 CD74825-C-5M-1Y-040M-2YRC-2M-0YRC \\
\hline Lalmi-02 & CIMMYT & Facultative & BOBWHITE/MN IC88-063-1AP-OL-1AP-2AP-OTS-OAP \\
\hline Pamir-94 & CIMMYT & Winter & YMH/TOB/3/LIRA SWM16 \\
\hline Koshan-09 & Afghanistan & Spring & $\mathrm{BABAX} / \mathrm{Lr} 42 / / \mathrm{BABAX} * 2 / \mathrm{VIVITSI}[3686]$ \\
\hline Lalmi-01 & ICARDA & Facultative & FOW-1 SWM11147-1AP-2AP-1AP-1AP-OAP \\
\hline Ariana-07 & CIMMYT & Facultative & Pastor/3/kauz*2/Opata//Kauz/CID/SID:133513/256 \\
\hline
\end{tabular}


Table 2 SSR Markers Name, Chromosomal Location and Number of Alleles Scored.

\begin{tabular}{|c|c|c|c|c|c|c|c|}
\hline Row & $\begin{array}{l}\text { Marker } \\
\text { Name }\end{array}$ & $\begin{array}{c}\text { Chromosomal } \\
\text { Location }\end{array}$ & $\begin{array}{c}\text { Number of } \\
\text { Alleles }\end{array}$ & Row & $\begin{array}{c}\text { Marker } \\
\text { Name }\end{array}$ & $\begin{array}{c}\text { Chromosomal } \\
\text { Location }\end{array}$ & $\begin{array}{c}\text { Number of } \\
\text { Alleles }\end{array}$ \\
\hline 1 & GWM164 & $1 \mathrm{~A}-\mathrm{L}$ & 3 & 33 & GWM251 & 4B-L & 8 \\
\hline 2 & GWM497 & 1A-L, 2A-L, 3D-L & 14 & 34 & GWM107 & 4B-L & 6 \\
\hline 3 & GWM259 & 1B-L & 10 & 35 & GWM149 & 4B-L & 6 \\
\hline 4 & GWM153 & $1 B-L$ & 11 & 36 & GWM608 & 4D-L & 4 \\
\hline 5 & GWM337 & $1 \mathrm{D}-\mathrm{S}$ & 11 & 37 & GWM156 & $5 \mathrm{~A}-\mathrm{L}$ & 3 \\
\hline 6 & GWM357 & $1 \mathrm{~A}-\mathrm{L}$ & 1 & 38 & GWM304 & $5 \mathrm{~A}-\mathrm{S}$ & 7 \\
\hline 7 & GWM274 & 1B-L, 7B-L & 6 & 39 & GWM335 & $5 \mathrm{~B}-\mathrm{L}$ & 5 \\
\hline 8 & GWM359 & $2 \mathrm{~A}-\mathrm{L}$ & 3 & 40 & GWM443 & $5 \mathrm{~B}-\mathrm{S}$ & 2 \\
\hline 9 & GWM558 & $2 \mathrm{~A}-\mathrm{S}$ & 4 & 41 & GWM554 & $5 B-L$ & 1 \\
\hline 10 & GWM372 & $2 \mathrm{~A}-\mathrm{L}$ & 3 & 42 & GWM371 & $5 B-L$ & 10 \\
\hline 11 & GWM55 & 2B-L & 15 & 43 & GWM540 & $5 B-S$ & 2 \\
\hline 12 & GWM148 & 2B-L & 6 & 44 & GWM639 & 5D-L & 9 \\
\hline 13 & GWM120 & 2B-L & 13 & 45 & GWM271 & 5D-L & 3 \\
\hline 14 & GWM249 & 2D-L & 8 & 46 & GWM190 & $5 \mathrm{D}-\mathrm{S}$ & 0 \\
\hline 15 & GWM210 & 2D-L & 5 & 47 & GWM427 & $6 \mathrm{~A}-\mathrm{L}$ & 8 \\
\hline 16 & GWM484 & 2D-L & 3 & 48 & GWM459 & $6 \mathrm{~A}-\mathrm{L}$ & 6 \\
\hline 17 & GWM539 & $2 \mathrm{D}-\mathrm{S}$ & 1 & 49 & GWM169 & $6 \mathrm{~A}-\mathrm{L}$ & 7 \\
\hline 18 & GWM102 & 2D-L & 6 & 50 & GWM334 & $6 \mathrm{~A}-\mathrm{L}$ & 5 \\
\hline 19 & GWM261 & 2D-L & 10 & 51 & GWM626 & $6 \mathrm{~B}-\mathrm{S}$ & 4 \\
\hline 20 & GWM32 & $3 \mathrm{~A}-\mathrm{S}$ & 6 & 52 & GWM70 & $6 \mathrm{~B}-\mathrm{L}$ & 0 \\
\hline 21 & GWM369 & $3 \mathrm{~A}-\mathrm{S}$ & 4 & 53 & GWM613 & $6 \mathrm{~B}-\mathrm{L}$ & 13 \\
\hline 22 & GWM247 & 3B-L & 9 & 54 & GWM132 & 6B-L & 7 \\
\hline 23 & GWM493 & 3B-L & 3 & 55 & GWM469 & 6D-L & 15 \\
\hline 24 & GWM340 & 3B-L & 6 & 56 & GWM325 & 6D-L & 5 \\
\hline 25 & GWM114 & $3 B-L$ & 16 & 57 & GWM233 & 7A-L & 1 \\
\hline 26 & GWM3 & 3D-L & 2 & 58 & GWM130 & 7A-L & 2 \\
\hline 27 & GWM314 & 3D-L & 10 & 59 & GWM60 & 7A-L & 5 \\
\hline 28 & GWM383 & 3D-L & 10 & 60 & GWM46 & 7B-S & 5 \\
\hline 29 & GWM165 & 4A-S, 4B-L, 4D-L & 1 & 61 & GWM43 & 7B-S & 10 \\
\hline 30 & GWM397 & $4 \mathrm{~A}-\mathrm{L}$ & 10 & 62 & GWM111 & 7D-L & 2 \\
\hline 31 & GWM160 & $4 \mathrm{~A}-\mathrm{L}$ & 10 & 63 & GWM44 & 7D-L & 9 \\
\hline 32 & GWM538 & 4B-L & 1 & 64 & GWM437 & 7D-L & 12 \\
\hline Mean & & & & & & & 6.29 \\
\hline
\end{tabular}

Table 3 AFLP Markers Name, Primer Sequences and Polymorphic Fragments Scored.

\begin{tabular}{c|ccccc}
\hline Row & MN* & \multicolumn{2}{c}{ Primer Sequence } & PFS \\
\hline 1 & E31/M47 & E31 5'GACTGCGTACCAATTCAAA & M47 5'GATGAGTCCTGAGTAACAA & 10 \\
2 & E31/M50 & E31 5'GACTGCGTACCAATTCAAA & M50 5'GATGAGTCCTGAGTAACAT & 16 \\
3 & E31/M52 & E31 5'GACTGCGTACCAATTCAAA & M52 5'GATGAGTCCTGAGTAACCC & 18 \\
4 & E31/M59 & E31 5'GACTGCGTACCAATTCAAA & M59 5'GATGAGTCCTGAGTAACTA & 17 \\
5 & E32/M47 & E32 5'GACTGCGTACCAATTCAAC & M47 5'GATGAGTCCTGAGTAACAA & 19 \\
6 & E32/M50 & E32 5'GACTGCGTACCAATTCAAC & M50 5'GATGAGTCCTGAGTAACAT & 15 \\
7 & E32/M52 & E32 5'GACTGCGTACCAATTCAAC & M52 5'GATGAGTCCTGAGTAACCC & 25 \\
8 & E32/M59 & E32 5'GACTGCGTACCAATTCAAC & M59 5'GATGAGTCCTGAGTAACTA & 17 \\
9 & E38/M47 & E38 5'GACTGCGTACCAATTCACT & M47 5'GATGAGTCCTGAGTAACAA & 10 \\
10 & E38/M50 & E38 5'GACTGCGTACCAATTCACT & M50 5'GATGAGTCCTGAGTAACAT & 8 \\
11 & E38/M52 & E38 5'GACTGCGTACCAATTCACT & M52 5'GATGAGTCCTGAGTAACCC & 22 \\
12 & E38/M62 & E38 5'GACTGCGTACCAATTCACT & M62 5'GATGAGTCCTGAGTAACTT & 14 \\
13 & E41/M47 & E41 5'GACTGCGTACCAATTCAGG & M47 5'GATGAGTCCTGAGTAACAA & 36 \\
14 & E41/M52 & E41 5'GACTGCGTACCAATTCAGG & M52 5'GATGAGTCCTGAGTAACCC & 21 \\
15 & E41/M62 & E41 5'GACTGCGTACCAATTCAGG & M62 5'GATGAGTCCTGAGTAACTT & 23 \\
16 & E46/M47 & E46 5'GACTGCGTACCAATTCATT & M47 5'GATGAGTCCTGAGTAACAA & 12 \\
17 & E46/M52 & E46 5'GACTGCGTACCAATTCATT & M52 5'GATGAGTCCTGAGTAACCC & 18 \\
18 & E46/M62 & E46 5'GACTGCGTACCAATTCATT & M62 5'GATGAGTCCTGAGTAACTT & 7 \\
\hline Mean & \multicolumn{5}{c}{} \\
\hline
\end{tabular}

MN: Marker Name, PFS: Polymorphic Fragments Score, ${ }^{*}$ This AFLP primers were abbreviated in accordance with the standard nomenclature of AFLPs (https://wheat.pw.usda.gov). ${ }^{* *}$ E: EcoRI adaptor, M: MseI adaptor.

Simple Sequence Repeats (SSRs) and Amplified Fragment Length Polymorphisms (AFLPS) analyses

Total genomic DNAs were isolated from each variety. Sixty-four SSR primer markers were used following Roder et al. (1998), see Table 2 for details. Also AFLP analysis was conducted by using enzyme combination EcoRI and MseI in accordance with method of Vos et al. (1995). Eighteen EcoRI+(N)/MseI+(N) primer combinations with their primer sequences were used for selective polymerase chain reaction (PCR) amplification (Table 3), (Eivazi et al, 2008).

Every SSR and AFLP fragment was scored as present (1) or absent (0) within all genotypes under study and to estimate the genetic similarities (GS) between pairs, binary matrix was used by applying Nei and Li coefficient (Nei and $\mathrm{Li}, 1979$ ). Therefore, the coefficient of dissimilarity (GD) between pairs calculated by GD = 1 - GS. A cluster analysis was carried out using the unweighted pair grouping method of arithmetic averages. The analyses 
were conducted with NTSYS-PC software (Rohlf, 2000). The support values for the level of confidence at the nodes of the AFLP, SSR and AFLP+SSR dendrograms were analyzed by 1000 bootstrap resampling using PHYLIP 3.57c computer software (Eivazi et al., 2008; Felsenstein, 1995).

\section{Results}

\section{SSRs Analyses}

Sixty-four wheat SSR loci produced a total of 491 alleles across all the genotypes related to grain yield and other agronomical traits under research. The number of alleles per locus ranged from 1 to 16 , with an average of 6.29 alleles per locus (See Table 2). Marker/ Value ratio of pairwise genetic distance between genotypes is measured. According to the SSRs data this ratio was from 0.508 to 0.691 with an average distance of 0.599 (Table 4). Relatively different grouping pattern in comparison to AFLP data observed through cluster analysis (Fig. 1). In the results of clusters, Koshan-09 and Lalmi-01 were placed in the same cluster and also Kabul-02 and Lalmi-03 were assigned in same cluster. Chonte was separated from Kabul-02 and grouped with Darulaman-07, Roshan-96 and Herat-99. In both data, Ariana-07 was distinct from the other clusters (Fig. 1 and Fig. 3), by considering of genetically content of them.

\section{AFLPs Analyses}

An analysis of amplified fragment length polymorphisms in 35 Afghan wheat genotypes based on eighteen primer combination constituted a total of 320 polymorphic amplified DNA fragments. Estimates of genetic diversity based on AFLP data varied from 0.425 to 0.819 with an average of 0.622 (Table 4). Grouping based on AFLP data revealed relative association with origin of genotypes region (Fig. 2). In the AFLP grouping, two genotypes, Ariana-07 and Mazar-99 originating from the north of Afghanistan were closely grouped together. Genotypes Lalmi-03, provided from ICARDA materials and Kabul-02, which have good tolerance to drought, were also clustered together, with high bootstrap value.

\section{AFLPs \& SSRs Analyses}

Amplified fragment length polymorphisms and SSR combined data analysis revealed a different grouping pattern compared with the individual methods. Based on this grouping, genotype Ariana-07 was differentiated from the others, which, has similar results of AFLP clustering analysis and Gul-98, Bakhtawar-92, Ghori-96, HD-2285, Inqlab-91, Balkh-66, Nangarhar-64, PBW-154, HUW-234, Dayma-96, Rana-96, Amu-99, Darulaman-07, Roshan-96, Herat-99 and Croc-01 showed very close relationships and grouped in one cluster (Fig. 3).

\section{Discussion}

Both types of molecular markers (AFLP and SSR) used in this research showed to be suitable for investigating genetic diversity in the genotypes of Afghan bread wheat. However, according to the Table 4, AFLP markers provided better view of genetically relationships among genotypes than the SSR markers. The grouping generated by AFLP data showed a special agreement with the origin regions of genotypes (Ariana-07 and Mazar-99 originating from the North of Afghanistan, Lalmi-03 obtained from ICARDA and Kabul-02. A large number of DNA bands identified with AFLP markers might provide a better estimation of genetic similarity than those of SSR markers in wheat and maize, respectively, (Almanza-Pinzon et al., 2003, Barbosa et al., 2003)

Table 4 Marker/Value ratio of pairwise genetic distance matrices based on SSR and AFLP Markers among 35 Afghan Bread Wheat Genotypes.

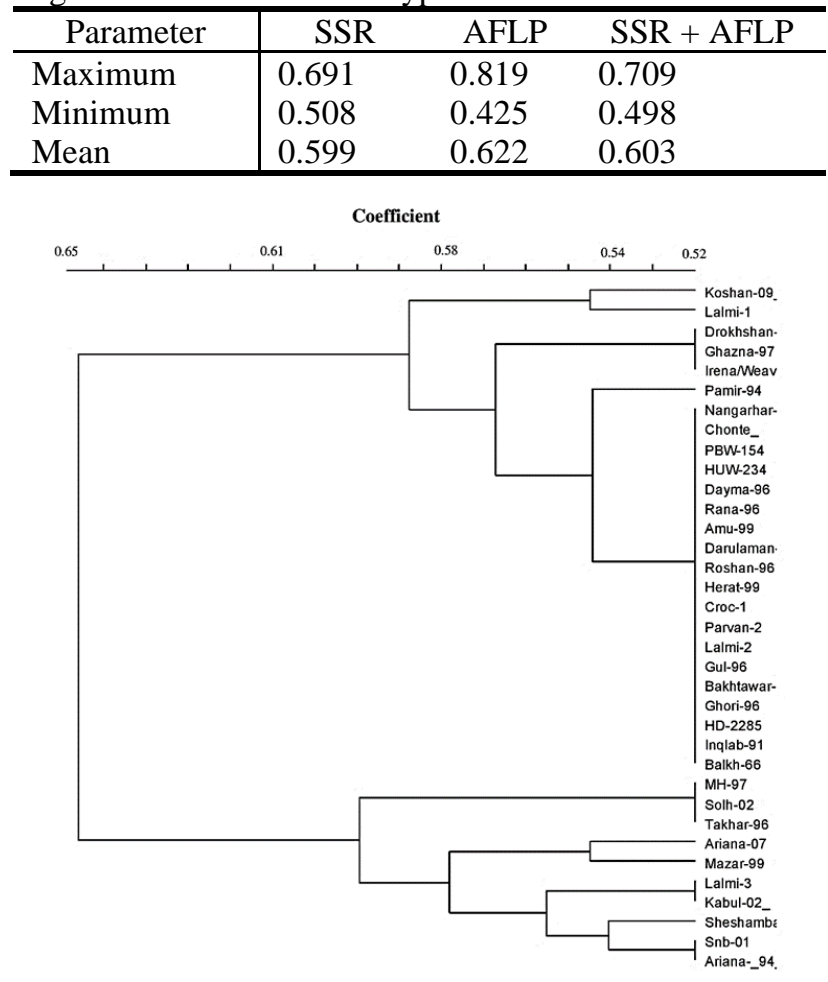

Figure 1 Arithmetic averages dendrogram of unweighted pair grouping method on 35 Afghan wheat genomes based on genetic distances computed from simple sequence repeats markers (SSRs), coefficients are bootstrap values

(\%) obtained from 1000 replicate analyses

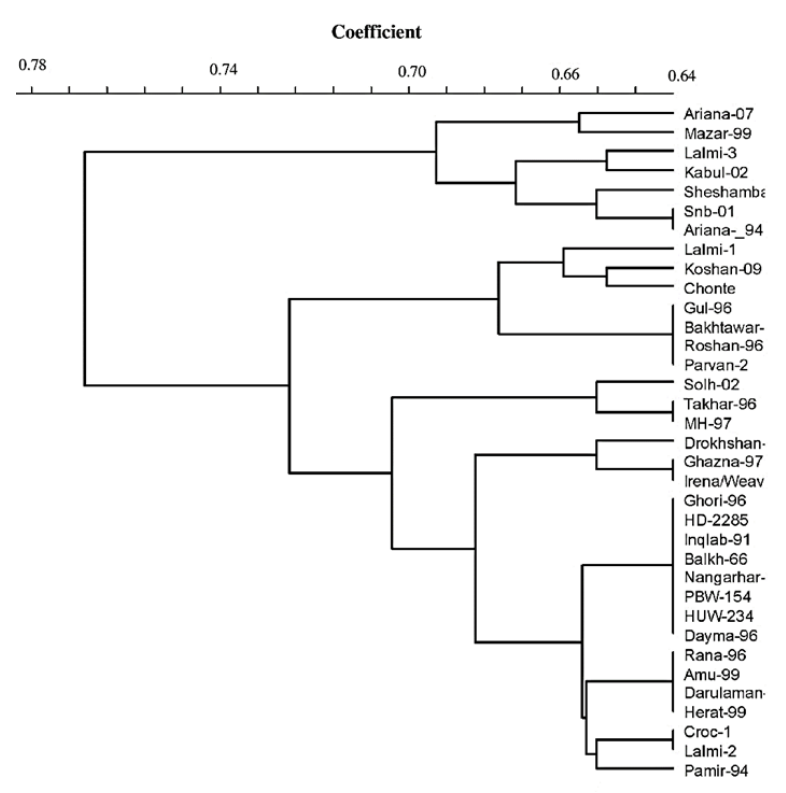

Figure 2 Arithmetic averages dendrogram of unweighted pair grouping method on 35 Afghan wheat genomes based on genetic distances computed from amplified fragment length polymorphisms (AFLPs), coefficients are bootstrap values $(\%)$ obtained from 1000 replicate analyses 
AFLP marker analysis by 18 clusters in genetic distance 0.64 (Fig. 2) is useful for identifying polymorphic molecular markers on the genotypes, Therefore, these markers were useful for evaluating genetic diversity among and within species (Shoaib et al., 2006, Altıntaş et al., 2007). As well by considering the highest mean of marker by value, 0.622 (Table 4) in genetic distance by AFLP technique, the primers developed for population are relevant to related taxa (Sasanuma et al., 2002).

\section{Conclusion}

In the study showed that collecting wheat germplasm from specific geographic region showed high genetic variation. Considering the importance of morphological assessment, the characterization of wheat gene pool by using DNA fingerprinting techniques such as marker assisted selection via AFLP and SSR molecular markers is an initial step in wheat breeding. This provides a tool to assess genetic diversity for finding high yield varieties. In summary, we conclude that the AFLP loci tested here in the genotypes, generally have more dominant inheritance versus SSR regions. The frequencies of polymorphic bands in diverse germplasm are in the range that enables mapbased diversity studies (Hazen et al., 2002). Furthermore, the magnitude and pattern of genetic variation observed in this study will be useful for wheat breeders to apply the genotypes as parents in the breeding programs.

\section{Acknowledgements}

This research is based on supported from Kabul University and Afghanistan's Ministry of Agriculture, Irrigation and Livestock. The authors would like to acknowledge with gratitude the financial support provided by the University Support and Workforce Development Program (USWDP).

\section{References}

Almanza-Pinzo' n MI, Khairallah M, Fox PN, Warburton ML. 2003. Comparison of molecular markers and coefficients of parentage for the analysis of genetic diversity among spring bread wheat accession. Euphytica, 130, 77-86.

Altıntaş S, Toklu F, Kafkas S, Kilian B, Brandolini A, \& Zkan HÖ.2007. Estimating Genetic Diversity in Durum and Bread Wheat Cultivars from Turkey using AFLP and SAMPL Markers. Plant Breeding, 0(0).

Barbosa AMM, Geraldi IO, Benchimol LL, Garcia AAF, Souza CLJr, Souza AP.2003. Relationship of intraand interpopulation tropical maize single cross hybrid performance and genetic distances computed from AFLP and SSR markers. Euphytica, 130, 87-99.

Casadesus J, Kaya Y, Bort J, Nachit MM, Araus JL, Amor S, Ferrazzano G, Maalouf F, Maccaferri M, Martos V, Ouabbou H, Villegas D.2007. Using vegetation indices derived from conventional digital cameras as selection criteria for wheat breeding in water-limited environments. Annals of Applied Biology, 150, 227-236.

Eivazi AR, Naghavi MR, Hajheidari M, Pirseyedi SM, Ghaffari MR, Mohammadi SA, Majidi I, Salekdeh GH, Mardi M. 2008. Assessing wheat (Triticum aestivum L.) genetic diversity using quality traits, amplified fragment length polymorphisms, simple sequence repeats and proteome analysis, Annals of Applied Biology 152, 81-91.

FAO report, global information and early warning system on food and agriculture (GIEWS), Country Brief- Afghanistan, 25 Sep 2017.
Felsenstein J.1995. PHYLIP (Phylogeny Inference Package) Version 3.57c. Seattle, WA, USA: Department of Genetics, University of Washington.

Fufa H, Baenziger PS, Beecher BS, Dweikat I, Graybosch RA, Eskridge KM.2005. Comparison of phenotypic and molecular marker-based classifications of hard red winter wheat cultivars. Euphytica, 145, 133-146.

Gupta PK, Balyan HS, Sharma PC, Ramesh B.1996. Microsatellites in plants: a new class of molecular markers. Current Science, 70, 45-54.

Hazen SP, Leroy P, \& Ward RW.2002. AFLP in Triticum aestivum L.: patterns of genetic diversity and genome distribution. Euphytica, 125(1), 89-102.

Mardi M, Pazouki L, Delavar H, Kazemi MB, Ghareyazie B, Steiner B, Nolz R, Lemmens M, Buerstmayr H.2006. QTL analysis of resistance to Fusarium head blight in wheat using a 'Frontana' derived population. Plant Breeding, 125, 313-317.

Naghavi MR, Mardi M, Pirseyedi SM, Kazemi M, Potki P, Ghaffari MR. 2007. Comparison of genetic variation among accessions of Aegilops tauschii using AFLP and SSR markers. Genetic Resources and Crop Evolution, 54, 237-240.

Nei M, Li W.1979. Mathematical model for studying genetic variation in terms of restriction endonucleases. Proceedings of the National Academy of Sciences of the United States of America, 76, 5269-5273.

Prasad M, Varshney RK, Roy JK, Balyan HS, Gupta PK. 2000. The use of microsatellites for detecting DNA polymorphism, genotype identification and genetic diversity in wheat. Theoretical and Applied Genetics, 100, 584-592.

Roder MS, Korzun V, Wendehake K, Plaschke J, Tixier MH, Leroy P, Ganal MW.1998. A microsatellite map of wheat. Genetics, 149, 2007-2023.

Rohlf FJ.2000. NTSYSpc, Numerical Taxonomy and Multivariate Analysis System. Version 2.1. Exeter Software. New York, USA: Applied Biostatistics Inc.

Sadeqi MB, Sarhadi WA, Peighambari SA, Naghavi MR, Kalbasi Ashtari A.2013. QTL analysis for Malt Quality in DH Lines of Barley (Steptoe $\times$ Morex) grown in Iran. Turkish Journal of Agriculture - Food Science and Technology, Vol 1, No 2 PP 56-61.

Saghai-Maroof MA, Soliman K, Jorgensen RA, Allard RW 1984. Ribosomal DNA spacer-length polymorphisms in barley: Mendelian inheritance, chromosomal location, and population dynamics. Proceedings of the National Academy of Sciences of the United States of America, 81, 8014-8018.

Salari MW, Sadeqi MB, Ongom PO, Saighani K, Samadi AF, Sarhadi WA.2015. Agronomic Performance of Exotic Wheat Lines under Kabul Agro-Ecological Conditions, Journal of Agriculture and Environmental Sciences, Vol. 4, No. 2, pp. 131-136.

Sasanuma T, Chabane K, Endo TR \& Valkoun J.2002. Genetic diversity of wheat wild relatives in the Near East detected by AFLP. Euphytica, 127(1), 81-93.

Shoaib A and Arabi M.2006. Genetic Diversity among Syrian Cultivated and Landraces Wheat Revealed by AFLP Markers. Genetic Resources and Crop Evolution, 53(5), pp.901-906.

Soleimani VD, Baum BR, Johnson DA.2002. AFLP and pedigreebased genetic diversity estimates in modern cultivars of durum wheat (Triticum turgidum L. subsp. Durum (Desf.)). Theoretical and Applied Genetics, 104, 350-357.

Van Beuningen LT, Busch RH.1997. Genetic diversity among North American spring wheat cultivars: III. Cluster analysis based on quantitative morphological traits. Crop Science, 37 , 981-988.

Vos P, Hogers R, Bleeker M, Reijans M, Van de Lee T, Hornes M, Frijters A, Pot J, Peleman J, Kuiper M, Zabeau M .1995. AFLP: a new technique for DNA fingerprinting. Nucleic Acids Research, 21, 4414-4470.

Wenguang C, Hucl P, Scoles G, Chibbar RN.1998. Genetic diversity within spelta and macha wheats based on RAPD analysis. Euphytica 104, 181-189. doi: 10.1023/A:1018628102650. 